\title{
Clinical and epidemiological profiles of non-traumatic myelopathies
}

\author{
Perfil clínico e epidemiológico das mielopatias não-traumáticas \\ Wladimir Bocca Vieira de Rezende Pinto, Paulo Victor Sgobbi de Souza, Marcus Vinícius Cristino de \\ Albuquerque, Lívia Almeida Dutra, José Luiz Pedroso, Orlando Graziani Povoas Barsottini
}

\begin{abstract}
Non-traumatic myelopathies represent a heterogeneous group of neurological conditions. Few studies report clinical and epidemiological profiles regarding the experience of referral services. Objective: To describe clinical characteristics of a non-traumatic myelopathy cohort. Method: Epidemiological, clinical, and radiological variables from 166 charts of patients assisted between 2001 and 2012 were compiled. Results: The most prevalent diagnosis was subacute combined degeneration (11.4\%), followed by cervical spondylotic myelopathy (9.6\%), demyelinating disease (9\%), tropical spastic paraparesis (8.4\%) and hereditary spastic paraparesis (8.4\%). Up to $20 \%$ of the patients presented non-traumatic myelopathy of undetermined etiology, despite the broad clinical, neuroimaging and laboratorial investigations. Conclusion: Regardless an extensive evaluation, many patients with non-traumatic myelopathy of uncertain etiology. Compressive causes and nutritional deficiencies are important etiologies of non-traumatic myelopathies in our population.

Keywords: spinal cord diseases, myelitis, paraparesis, myelopathy.

\section{RESUMO}

As mielopatias não-traumáticas representam um grupo heterogêneo de doenças neurológicas. Poucos estudos descrevem os perfis clínico e epidemiológico sobre a experiência de serviços de referência. Objetivo: Descrever as características clínicas de uma coorte de mielopatia não-traumática. Método: Os registros clínicos de 166 pacientes atendidos entre 2001 e 2012 foram revisados e variáveis epidemiológicas, clínicas e radiológicas foram compiladas. Resultados: 0 diagnóstico mais prevalente foi o de degeneração combinada subaguda (11,4\%), seguido por mielopatia espondilótica cervical (9,6\%), doenças desmielinizantes (9\%), paraparesia espástica tropical $(8,4 \%)$ e paraparesia espástica hereditária (8.4\%). Aproximadamente $20 \%$ dos pacientes apresentaram mielopatia não-traumática de etiologia indeterminada, apesar da ampla investigação clínica, laboratorial e de neuroimagem. Conclusão: Independentemente da ampla avaliação, muitos pacientes com mielopatia não-traumática apresentam etiologia incerta. Causas compressivas e deficiências nutricionais permanecem como etiologias importantes de mielopatias não-traumáticas.
\end{abstract}

Palavras-chave: doenças medulares, mielite, paraparesia, mielopatia.

Non-traumatic spinal cord diseases constitute one of the most common groups of neurological diseases in medical practice ${ }^{1}$. It is a broad and heterogeneous group of etiologies, summarily divided into compressive and non-compressive, among which include infectious, demyelinating, neoplastic, metabolic and vascular diseases and congenital malformations. Medical comorbidities and epidemiological data are important tools combined with complete physical examination to determine specific diagnostic suspicion ${ }^{2,3,4}$.

Most diagnostic algorithms do not take into account individual data or prevalence each disease or prevalence in a given population; rather they involve information on clinical course of myelopathy, neuroimaging and other complementary investigation. Although we apply the same diagnostic flowcharts in our population, many etiologies are known to be distinct in our context, notably the higher prevalence of infectious causes. Moreover, the use of flowcharts without appropriated clinical context increases the health system costs, while maintaining the high percentage of undefinited etiology cases. The aim of this study was to describe a large cohort of patients with non-traumatic myelopathy from a neurological reference service in Brazil. 


\section{METHOD}

A retrospective observational review from 1050 medical records of patients was performed and 166 patients with suspected myelopathy. Our study was approved by our institutional Ethics Committee. All patients were followed for at least 2 years and underwent clinical, laboratorial, neuroimaging and genetic evaluation. Inclusion criteria were patients of any age or gender, who presented at the initial clinical examination with one or more clinical signs suggestive of possible myelopathy: sphincter dysfunction, paraparesis, tetraparesis, sensory level, clinical compromise of multiple ascendants or descendants tracts and/or a specific spinal cord syndrome (complete, posterior cord, anterior horn, foramen magnum, central cord, conus medullaris, cauda equina, Brown-Séquard and tractopathies) ${ }^{2,3,5,6}$.

Information on age, gender, age at onset, disease duration, first clinical complaint, personal and familial medical history, myelopathy severity (European-Myelopathy Score (EMS), Cooper-myelopathy-scale(CMS),Prolo-scoreand Nurick-score) ${ }^{7}$, neuroimaging studies (spinal cord MRI, eventually all neuraxial), general and specific laboratory exams (routine rheumatology profile; serum vitamin B12; angiotensin-converting enzyme; CMV antigenemia assay; HIV, HTLV-I/II, syphilis, hepatitis B and $\mathrm{C}$ serologies; serum very long-chain fatty acids; serum and urinary ceruloplasmin and copper; serum anti-aquaporin-4 antibody), specific cerebrospinal fluid studies (viral and syphilis serologies and oligoclonal bands) ${ }^{3,5,8}$, and electroneuromyography study findings (in doubtful etiology or need for additional diagnostic strategy) were compiled.

\section{RESULTS}

\section{Clinical and epidemiological data}

There was a slight male predominance (53\%) in our sample. The mean age at diagnosis $48.5 \pm 16.2$ years and mean disease duration of $49.9 \pm 34.5$ months.
The most common complaints were paraparesis $(41.6 \%$; $\mathrm{n}=69)$ and paresthesia/numbness in the lower limbs (36.1\%; $\mathrm{n}=60$ ), followed by hypoesthesia in the lower limbs (18.7\%; $\mathrm{n}=31$ ), back pain (17.5\%; $\mathrm{n}=29)$, monoparesis (13.8\%; $\mathrm{n}=23)$, lower limbs pain $(12.0 \% ; \mathrm{n}=20)$, imbalance $(9.0 \%$; $\mathrm{n}=15)$, recurrent falls $(7.2 \% ; \mathrm{n}=12)$, sphincter disturbance $(6.0 \% ; \mathrm{n}=10)$, stiffness in the lower limbs $(5.4 \% ; \mathrm{n}=9)$ and tetraparesis $(4.8 \% ; \mathrm{n}=8)$.

Most patients presented progressive $(53 \% ; \mathrm{n}=88)$ and stable $(45.2 \% ; n=75)$ clinical courses, with only $2 \%(n=3)$ of cases presenting recurrent deficits, all revealing demyelinating disease. Only half of patients presented sphincter impairment complaint (51.2\%), more frequently urinary incontinence (35.5\%) and constipation (36.7\%). Fecal incontinence was observed in less than $10 \%$ of cases. Double sphincter impairment was most common in neuroschistosomiasis, possibly related to lesions near the conus medullaris. Evidence of sensory level in the physical examination was absent in $73.5 \%(\mathrm{n}=122)$ of cases, and the most common level was the thoracic $(20.5 \% ; \mathrm{n}=34)$. Cervical level was rarely observed $(1.8 \% ; \mathrm{n}=3)$.

Regarding previous medical history of chronic clinical and surgical conditions, draws attention the fact that only $4 \%$ of patients do not have medical backgrounds, as well as the high prevalence of previous malignancies (13.8\%) (Table 1). A positive family history (parents, siblings) for a known etiology of myelopathy was absent in this sample. However, up to $10 \%$ of patients presented with a family history of stroke, $2.4 \%$ $(n=4)$ with monoparesis of unknown etiology, and less than $2 \%$ with family history of epilepsy, Parkinson's disease, myasthenia gravis and X-linked adrenoleukodystrophy. Parental consanguinity was present in only 3 cases.

The most frequent non-traumatic etiologies were subacute combined degeneration (11.4\%), cervical spondylotic myelopathy (9.6\%), demyelinating disorders (9\%), HTLVrelated tropical spastic paraparesis (8.4\%), hereditary spastic paraparesis $(4.8 \%)$ and schistosomal myeloradiculopathy (3.6\%) (Table 2). Undefined etiology represented $20.5 \%$ of

Table 1. Group of medical comorbidities and prior clinical conditions presented by patients in this study $(n=166)$. Only 7 patients $(4,2 \%)$ did not show any significant past medical history. Percentage among myelopathic patients are represented between brackets.

\begin{tabular}{|c|c|}
\hline Relative frequency & Relevant past medical history \\
\hline$>25 \%$ & Smoking (39.2\%), hypertension (30.7\%), alcoholism (26.5\%). \\
\hline $10-25 \%$ & Prior malignancy (13.8\%), hypercholesterolemia (13.2\%), depression (11.5\%), hypothyroidism (10.2\%). \\
\hline $5-10 \%$ & $\begin{array}{c}\text { Chronic gastritis and hypertriglyceridemia (9.6\%), urinary tract infection repeat (8.4\%), diabetes mellitus type } 2 \\
\text { (7.8\%), megaloblastic anemia (6.0\%). }\end{array}$ \\
\hline$<5 \%$ & $\begin{array}{l}\text { 4.8\%: AIDS. } \\
\text { 4.2\%: Schistosomiasis, Helicobacter pylori infection, prior sexually transmitted diseases. } \\
3 \% \text { : epilepsy, primary headache, deep vein thrombosis. } \\
\text { 2.4\%: Hepatitis C vírus infection, prior pulmonary tuberculosis. } \\
\text { malignancy, cirrhosis. } \\
\text { 1.8\%: abortions, morbid obesity, viral poliomyelitis, prior stroke and acute myocardial infarction, hematologic } \\
\text { 1.2\%: herpes zoster, parkinsonism, chronic atrial fibrillation, illicit drug abuse, Chagas disease. } \\
\text { thromboembolism, histiocytosis, diabetes mellitus type 1. }\end{array}$ \\
\hline
\end{tabular}


cases. In cases of hereditary spastic paraparesis, genetic testing for each subtype was routinely unvailable in our service, regarding the diagnosis in familial patterns of neurological involvement and neuroimaging findings. Paraneoplastic etiology was not evinced in our sample. Spondylotic cervical myelopathy was the cause with higher average age of patients at diagnosis. Demyelinating diseases, tropical spastic paraparesis and Chiari type I malformation presented the profile of younger patients, as well as neuroschistosomiasis although some patients discrepant.

Regarding the functional clinical severity scale applied (European myelopathy score/EMS) and other myelopathy scores (Cooper myelopathy score, Prolo-Score, Nurick-Score), there was no correlation of greater or lesser severity and functional impairment with specific etiologies (Table 3).

\section{Laboratory results and spinal fluid analysis}

Serum evaluation was performed in all patients. Laboratorial serum screening disclosed important results defining diagnosis of B12 vitamin deficiency, tropical spastic paraparesis, adrenomyeloneuropathy and neuromyelitis optica (Table 4). There was a direct association of cases with high eosinophilic contents in the cerebrospinal fluid and schistosomal myeloradiculopathy.

\section{Neuroimaging and neurophysiological studies}

Neuroimaging studies were routinely done in all patients with at least one cervical and thoracic spine MRI, which in some cases was supplemented with cranial and lumbosacral imaging. In $24 \%(n=40)$ of cases, neuroimaging evaluation

Table 2. Main etiological groups of non-traumatic myelopathies, according to initial clinical suspicion and to definitive diagnosis ( $n=166)$. Percentage among myelopathic patients are represented between brackets.

\begin{tabular}{|c|c|}
\hline Etiological groups & Relative frequency \\
\hline Initial clinical suspicion & $\begin{array}{l}\text { Undefined (36.1\%; } n=60) \text {, Compressive }(21.1 \% ; n=35) \text {, Subacute combined degeneration (vitamin B12 } \\
\text { deficiency) }(11.4 \% ; n=19) \text {, Demyelinating }(9.0 \% ; n=15) \text {, Hereditary spastic paraparesis }(3.6 \% ; n=6) \text {, } \\
\text { Chiari type I malformation, Schistosomal myeloradiculopathy, Tropical spastic paraparesis }(3.0 \% ; n=5) \text {, } \\
\text { Postinfectious myelitis }(2.4 \% ; n=4) \text {, Adrenomyeloneuropathy, syringomyelia, Motor Neuron Disease }(1.8 \% \text {; } \\
n=3) \text {. Others: spinal cord malformations }(1.2 \% ; n=2) \text {, HIV-associated vacuolar myelopathy }(0.6 \% ; n=1) \text {. }\end{array}$ \\
\hline Definitive diagnosis & 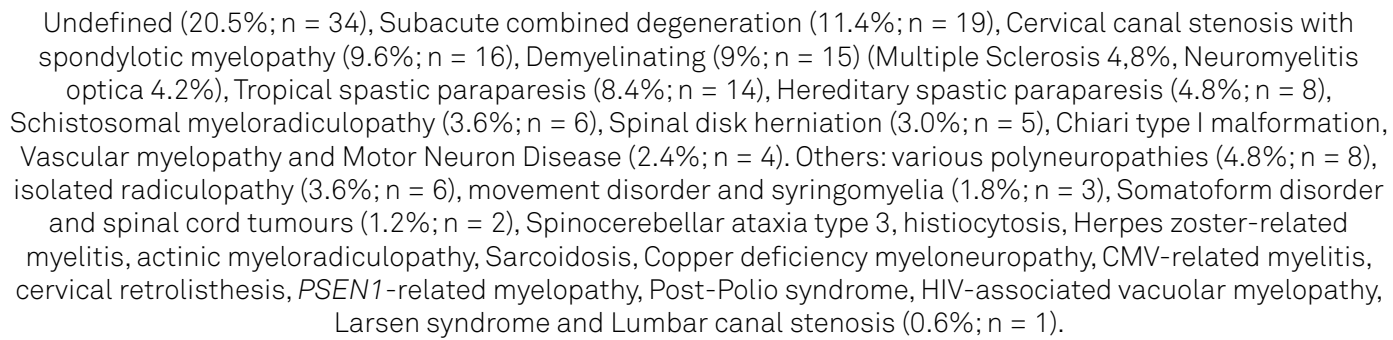 \\
\hline
\end{tabular}

Table 3. Results from functional clinical severity scale and other myelopathy scores.

\begin{tabular}{|c|c|}
\hline Scale used & Main results \\
\hline EMS & $\begin{array}{l}\text { 48\% score I (mild deficits), } 19.3 \% \text { score II (moderate deficits), <5\% score } \\
\text { III (severe deficits) }\end{array}$ \\
\hline CMS (upper and lower limbs compromise) & $\begin{array}{c}3.6 \% \text { with } 7 \text { to } 8 \text { points (maximum scores), } 4.2 \% \text { with zero score (minimum score), } \\
70 \% \text { with scores } 1 \text { to } 6 \text { ( } 60 \% \text { with scores } 1 \text { to } 3 \text { ) }\end{array}$ \\
\hline Nurick score (severity of functional impairment) & $\begin{array}{c}48 \% \text { with scores } 2 \text { to } 3 \text { (moderate functional impairment), } 26 \% \text { with scores higher or } \\
\text { equal to } 4 \text { (severe) }\end{array}$ \\
\hline Prolo score (economic and functional scale) & $60 \%$ with grades II/III, $20.5 \%$ with grade I, $4.2 \%$ with normal values (grade 0) \\
\hline
\end{tabular}
EMS: European Myelopathy Score; CMS: Cooper Myelopathy Score.

Table 4. Main serum and cerebrospinal fluid laboratory and neuroimaging results.

\begin{tabular}{|c|c|}
\hline Additional tests & Main results \\
\hline Serum laboratorial screening results & $\begin{array}{c}11.4 \% \text { with cobalamin deficiency, } 10.2 \% \text { with high MCV, } 9 \% \text { with positive ANA, } 4.2 \% \text { with } \\
\text { positive HTLV-I/II serologic test, } 4.2 \% \text { with positive anti-aquaporin- } 4 \text { antibodies, < } 2 \% \\
\text { with high VLCFA, } 0.6 \% \text { with copper deficiency }\end{array}$ \\
\hline Cerebropinal fluid examination & $\begin{array}{l}3.6 \% \text { with albuminocytologic dissociation, } 3.6 \% \text { with positive oligoclonal bands, } 1.2 \% \\
\text { with hypereosinophilic content (> 10\% of total pleocytosis) }\end{array}$ \\
\hline Neuroimaging findings & $\begin{array}{l}23.5 \% \text { with non-compressive signal changes in any segments in T2/FLAIR images; } \\
9.6 \% \text { of cases with cervical spine stenosis ( } 16.9 \% \text { of all cases with intervertebral disc } \\
\text { protrusions in the cervical segment) }\end{array}$ \\
\hline Neurophysiological studies & $\begin{array}{l}1.8 \% \text { with anterior horn cell compromise; } 24.2 \% \text { with demyelinating polyneuropathy; } \\
5.4 \% \text { with isolated axonal polyneuropathy; } 3.6 \% \text { with isolated radiculopathy }\end{array}$ \\
\hline
\end{tabular}


was unremarkable, and spinal cord signal changes were seen in less than a half of cases (Table 4). Some case examples are displayed in Figure 1.

Electroneuromyography studies were performed in only $32 \%$ of cases, mainly in cases with suspected motor neuron disease, radiculopathies and myeloneuropathies, independently from the main suspicion causes in such cases. Normal results were observed in $14.5 \%$ of cases. However, in less than $2 \%$ of cases defined the diagnosis of amyotrophic lateral sclerosis and aided the definite diagnosis of isolated radiculopathies and polyneuropathies (Table 4).

\section{DISCUSSION}

This study provides an interesting face of the main clinical, epidemiological and neuroimaging findings of patients with non-traumatic myelopathies in our midst. Therefore, our sample provides a relevant view on the most common causes of non-traumatic myelopathies.

In Cameroon, an underdeveloped country, non-traumatic myelopathies are more commonly associated with compression, with $24.5 \%$ of cases accounting for neoplastic disease, $12.9 \%$ for spinal tuberculosis and $4.1 \%$ for cervical spondylotic myelopathy. Other etiologies were such as for tropical spastic paraparesis (4.8\%), 1.4\% for HIV-related vacuolar myelopathy (1.8\%), and for multiple sclerosis and subacute combined degeneration $(0.7 \%)$ are rarely reported ${ }^{9}$. No etiology was found in $21.1 \%$ of cases. In our population we found higher prevalence of vitamin B12 deficiency and demyelinating diseases.

Another large study was performed in Liverpool, England, in a 3-year-period with 585 patients with paraparesis or spastic quadriplegia, which revealed as major causes of nontraumatic myelopathies cervical spondylotic myelopathy (23.6\%), multiple sclerosis $(17.8 \%)$, extrinsic spinal cord neoplasia
$(16.4 \%)$ and motor neuron disease $(4.1 \%)^{10}$. It has also shown that in $18.6 \%$ of cases no specific etiologies were found, even after thorough etiologic investigation. In this study also the occurrence of neoplasms was higher and the low prevalence of subacute combined degeneration. Interestly, the percentage of patients with uknown etiology in both studies was very similar to our results, unvealing the difficulties inherent in defining diagnosis of non-traumatic spinal cord diseases. It is essential to disclose that our neurological service has specific neurological units which also receive subspecialty cases and, thus, can explain one of the reasons for a low prevalence of neoplastic (such as spinal cord tumors), motor neuron disease (such as primary lateral sclerosis) and demyelinating disorders (such as neuromyelitis optica and multiple sclerosis).

Other important contributions were obtained from our study: (i) in most cases of non-traumatic myelopathy family history is of little relevance; (ii) structural causes, including spondylotic cervical myelopathy, generally present with a longer symptom duration period; (iii) double and severe sphincter compromise are highly suggestive signs of schistosomiasis in our population; (iv) clinical severity of a myelopathy do not keep a direct relation to a specific etiology; (v) all pure motor syndromes should be evaluated with neurophysiological studies after a normal neuroimaging study to search for motor neuron disease, even in the absence of bulbar symptoms at presentation; (vi) the youngest patients were those with demyelinating diseases, tropical spastic paraparesis, Chiari type I malformation and cases of neuroschistosomiasis without prominent pain complaints, as well as cervical spondylotic myelopathy represents the main cause of non-traumatic myelopathy in the elderly. Through these findings and the current literature, we developed a complementary flowchart with a basic diagnostic algorithm for non-traumatic myelopathy evaluation in our population (Figure 2).
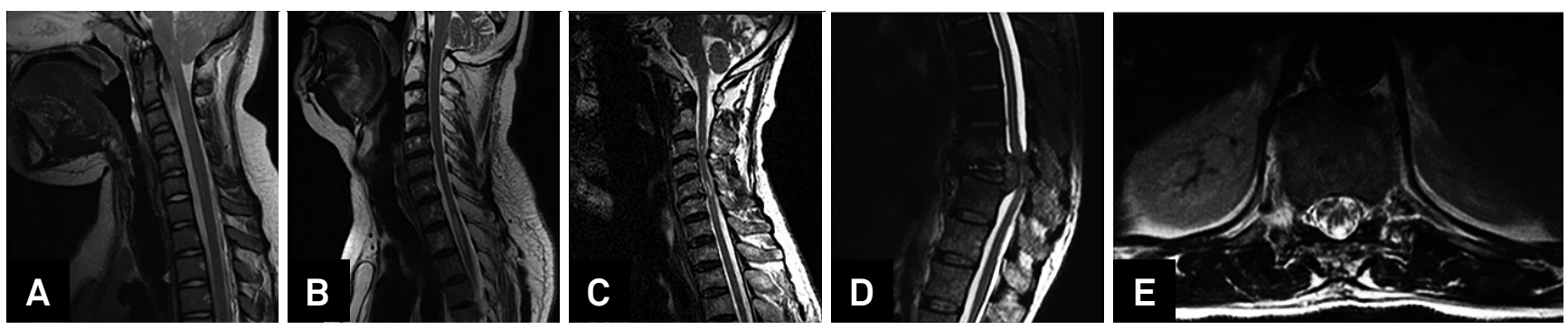

Figure 1. Some spinal cord MRI examples. (A) A 40-year-old man with a 8-month history of paraparesis, upper and lower limbs paresthesias with no sphincter dysfunction and a sagittal MRI section suggestive of Chiari type I malformation; (B) A 48-year-old man with a progressive history of recurrent longitudinally extensive transverse myelitis and a sagittal MRI section suggestive of a demyelinating disease with positive anti-aquaporin-4 antibody; (C) A 68-year-old man with a 4-month history of shoulder muscles twitching and weakness to lift objects with no sphincter dysfunction, and cervical spine MRI suggestive of cervical spondylotic myelopathy; (D) A 52-year-old man with a 3-week-progressive paraparesis with sagittal MRI section showing a pathological fracture of T10 vertebra originating from an extensive pedicular mass and giving rise to a compressive thoracic myelopathy from a neoplastic lesion (pathological diagnosis: plasmacytoma); (E) A 36-year-old woman with exacerbation of chronic low back pain associated with urinary sphincter dysfunction, paraparesis and hypoesthesia in the lower limbs, positive serological tests for schistosomiasis and transverse MRI section showing a T10-T11 level hyperintensity predominantly in dorsal roots, posterior column and lateral corticospinal tract, suggestive of schistosomal myeloradiculopathy. 
Signs and symptoms of myeloradicular syndrome, tetraparesis, paraparesis, sphincter dysfunction, sensory level, specific spinal cord syndrome, Lhermitte sign

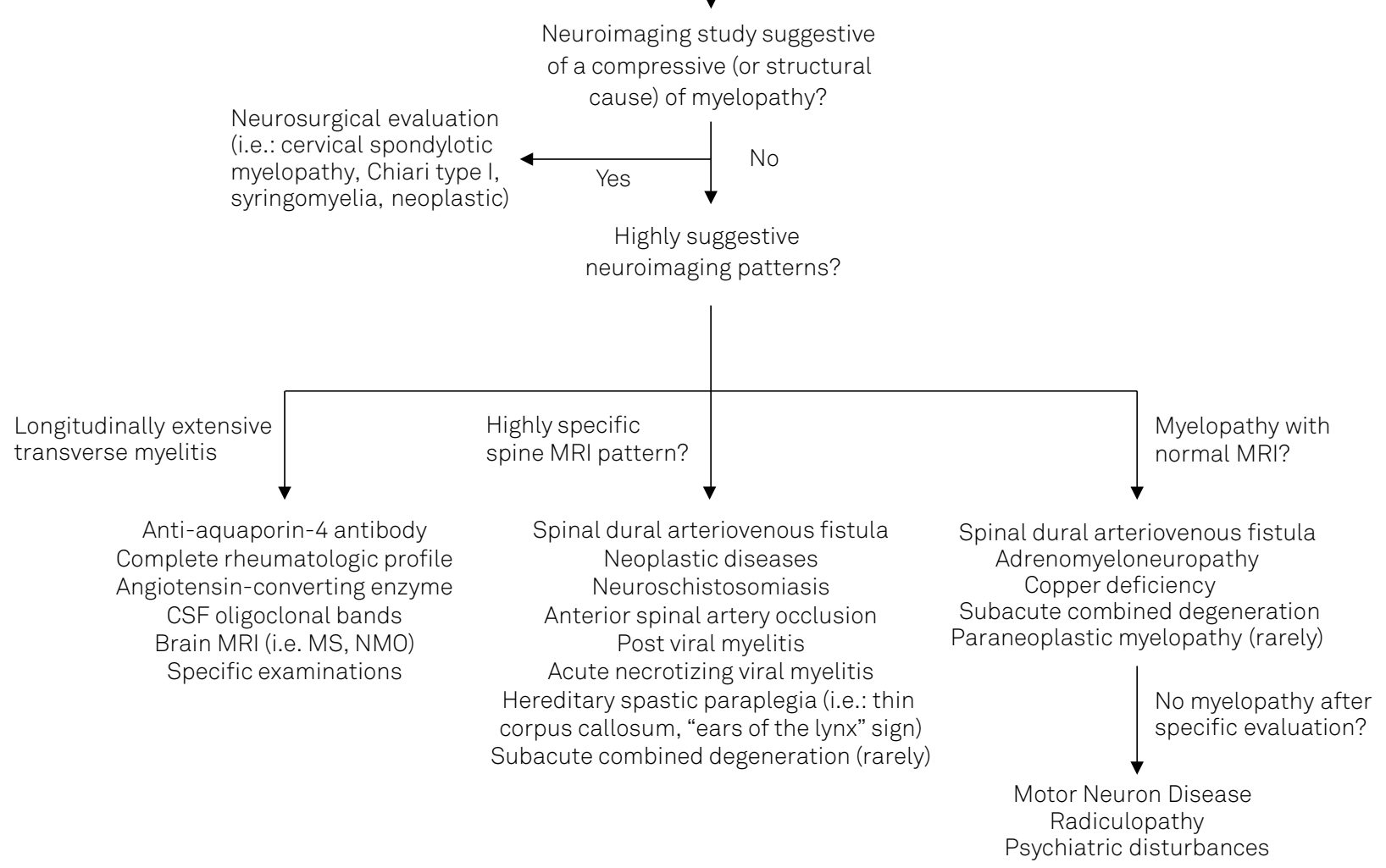

NMO: neuromyelitis optica; MS: multiple sclerosis.

Figure 2. Myelopathy algorithm. A proposed algorithm to evaluate nontraumatic myelopathies and its main differential diagnosis.

This is a relevant study that describes the clinical and epidemiological profiles, scales of severity and etiology of nontraumatic myelopathy, enabling the comparison and understanding of spinal cord diseases in our clinical context, although the data come from our reference service, not fully effectively representing population data.

\section{References}

1. Ginsberg L. Disorders of the spinal cord and roots. Pract Neurol. 2011:11(4):259-67. doi:10.1136/practneurol-2011-000069

2. Schwenkreis P, Pennekamp W, Tegenthoff M. Differential diagnosis of acute and subacute non-traumatic paraplegia. Dtsch Arztebl. 2006;103(44):A2948-54

3. Schmalstieg WF, Weinshenker BG. Approach to acute or subacute myelopathy. Neurology. 2010;75(18 Suppl 1):S2-8. doi:10.1212/WNL.0b013e3181fb3638

4. Brinar VV, Habek M, Zadro I, Barun B, Ozretić D, Vranjes D. Current concepts in the diagnosis of transverse myelopathies. Clin Neurol Neurosurg. 2008;110(9):919-27. doi:10.1016/j.clineuro.2008.07.002

5. Jacob A, Weinshenker BG. An approach to the diagnosis of acute transverse myelitis. Semin Neurol. 2008;28(1):105-20. doi:10.1055/s-2007-1019132
6. Hess ChW. [Non-traumatic acute transverse spinal cord syndromes]. Praxis (Bern 1994). 2005;94(30-31):1151-9. German.

7. Vitzthum HE, Dalitz K. Analysis of five specific scores for cervical spondylogenic myelopathy. Eur Spine J. 2007;16(12):2096-103. doi:10.1007/s00586-007-0512-x

8. Wong SH, Boggild M, Enevoldson TP, Fletcher NA. Myelopathy but normal MRI: where next? Pract Neurol. 2008;8(2):90-102. doi:10.1136/jnnp.2008.144121

9. Lekoubou Looti AZ, Kengne AP, Djientcheu VP, Kuate CT, Njamnshi AK. Patterns of non-traumatic myelopathies in Yaoundeé (Cameroon): a hospital based study. J Neurol Neurosurg Psychiatry. 2010;81(7):76870. doi:10.1136/jnnp.2009.177519

10. Moore AP, Blumhardt LD. A prospective survey of the causes of non-traumatic spastic paraparesis and tetraparesis in 585 patients. Spinal Cord. 1997;35(6):361-7. doi:10.1038/sj.sc.3100422 